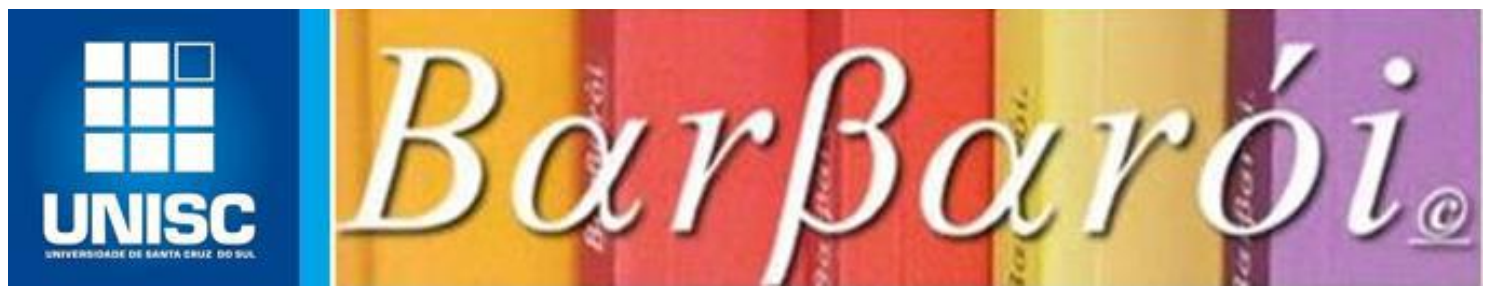

\title{
TRABALHO DOCENTE: VALORIZAÇÃO OU INTENSIFICAÇÃO E ESVAZIAMENTO DA PROFISSÃO?
}

\author{
DOI: http://dx.doi.org/10.17058/barbaroi.v1i53.7688
}

\author{
$*$ \\ Élida Furtado do Nascimento \\ Universidade Federal do Acre - UFAC - Brasil \\ Luís Alberto Lourenço Matos \\ Universidade Federal de Rondônia - UNIR - Brasil \\ Marli Lúcia Tonatto Zibetti \\ Universidade Federal de Rondônia - UNIR - Brasil

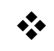

\section{Resumo}

O ensaio objetiva, ao sistematizar algumas ideias a partir de autores que têm discutido a intensificação e esvaziamento da profissão docente, analisar a função docente nas políticas educacionais de cunho neoliberal a partir das contribuições da Psicologia Histórico-Cultural, discutindo a valorização do papel da educação escolar e do professor na formação humana. A partir do que diferentes autores trazem sobre as influências dos valores neoliberais nas políticas educacionais e, consequentemente, na redefinição do papel docente, propõe-se o aporte teórico da Psicologia Histórico-Cultural como reflexão sobre possíveis formas de enfrentamento das ideologias neoliberais de desvalorização da profissão. O texto identifica no primeiro momento o papel da educação e do professor nas políticas educacionais após os anos 1990 e, no segundo, apresenta algumas contribuições da Psicologia Histórico-Cultural para pensar o papel contributivo da educação e do professor na formação humana como contraponto ao que está posto.

Palavras-chave: Neoliberalismo. Psicologia Histórico-Cultural. Trabalho docente.

\section{Introdução}

O papel da educação formal e, em particular, o trabalho docente na educação básica, é uma das temáticas que permeia o debate no campo educacional e áreas afins, principalmente a partir da redefinição do papel do Estado na sociedade globalizada e sob as diretrizes do Banco Mundial como um dos organismos internacionais que tem ditado o rumo das reformas do Estado, ocorrido a partir da década de 1990. Os valores neoliberais no contexto educacional passam a ser materializados pela Lei de Diretrizes e Bases da Educação de 1996 (LDB 
9394/96) e nas políticas educacionais de formação de professores, de avaliação, entre outras, desenvolvidas desde então. Nesse contexto, o presente texto se insere no debate sobre as implicações dessas políticas no processo de intensificação e esvaziamento do trabalho docente, mas que aparece sob o disfarce de valorização da docência.

A função docente, na análise de Assunção e Oliveira (2009, p. 352) se amplia a partir das definições LDB 9.394/96,

[...] nos seus artigos 12, 13 e 14, dispõe sobre as competências dos estabelecimentos de ensino e dos docentes e, ainda, sobre a gestão democrática, reforçando tais tendências e demonstrando que no plano legal o trabalho docente não se restringe à sala de aula, mas que ele contempla ainda as relações com a comunidade, a gestão da escola, o planejamento do projeto pedagógico, a participação nos conselhos, entre outras funções. Assim, podemos considerar que houve uma dilatação, no plano legal, da compreensão do que seja o pleno exercício das atividades docentes.

O aumento da carga horária e exigência de participação coletiva nas atividades da escola, sem falar no aumento do número de alunos por turma, têm contribuído para o esvaziamento das forças do professor. Aumentou-se o trabalho e as demandas na educação, mas não se aumentou o efetivo. As condições materiais de trabalho, na maioria das escolas, permaneceram as mesmas.

Além do aumento do volume de tarefas, passa a ser cobrada da escola melhor qualidade do ensino. As avaliações externas sejam elas de nível estadual, nacional ou internacional estão aí para julgar tal qualidade da educação e, consequentemente, do trabalho do professor. Tudo isso, feito sob a pressão das críticas externas, que cobram que a educação dê conta de resolver todas as demandas da sociedade sozinha, sem as devidas condições. "Diante da ampliação das demandas trazidas pelas políticas mais recentes, o professor é chamado a desenvolver novas competências necessárias para o pleno exercício de suas atividades docentes" (ASSUNÇÃO; OLIVEIRA, 2009, p. 355).

Por outro lado, o discurso oficial, veiculado pela mídia, e lastreado no senso comum, tenta mascarar essa realidade ao defender a importância do professor para o desenvolvimento da sociedade. Tal contradição coloca o professor em situação ambígua: de um lado o discurso oficial, reforçado pela mídia, o valoriza. Por outro, sua função de ensinar tem sido esvaziada em meio às concepções e condições de ensino da escola pública. Essa ambiguidade tem consequências, tais como: desvalorização social do papel do professor, inclusive refletindo nos baixos salários e na crítica à qualidade da educação pública; adoecimento docente; abandono da carreira e a frequente desistência dos estudantes dos cursos de licenciaturas, com sinais cada vez mais visíveis da desvalorização da profissão docente. 
O esvaziamento da função docente como aquele a quem compete ensinar e, ao mesmo tempo, a intensificação de seu trabalho, tem permeado as discussões de setores da educação e de áreas afins. Essas discussões parecem carregadas de angústia, inquietação e sofrimento, por parte de muitos professores, que se percebem, cada vez mais, engessados frente às exigências da profissão, em um contexto de valorização desmedida do lucro capitalista. De tal modo que a implantação e implementação de políticas educacionais de cunho neoliberal tendem a usurpar tempo, privacidade, ousadia e sonhos de grande parte dos profissionais da educação, interferindo na identidade profissional.

O enfoque de cunho neoliberal nas políticas educacionais é marcado por um discurso contraditório. Por um lado, pela defesa do papel ideológico da escola (DUARTE, 2010), a classe docente é designada a resolver os problemas de ordem social, cultural, política e econômica por meio da educação escolar. Desse modo, captura os desejos mais íntimos de homens e mulheres que ainda acreditam nas possibilidades da educação escolar como transformadora dessa sociedade. Por outro lado, se utilizando do mesmo discurso, intensificam-se as cobranças por resultados positivos, demandando mais trabalho e retirando do professor sua verdadeira identidade, a de agir de forma intencional e organizada na construção dos conhecimentos científicos historicamente construídos pela humanidade.

Pensar tal realidade exige, na perspectiva dialética de Vigotski (2003), a análise de dimensões maiores em que o trabalho docente se concretiza. Isso significa olhar para o papel das influências neoliberais nas políticas educacionais e, consequentemente, para a função docente

Ao se discutir sobre a intensificação do trabalho docente precisaria ir além da realidade aparente, pois esse primeiro olhar leva a culpabilizar uns e outros por tal situação, sem se dar conta do emaranhado em que, não somente o professor, mas a sociedade de forma geral está imersa, frente às demandas das influências neoliberais no campo educacional.

Nesse sentido, o presente ensaio visa, ao sistematizar algumas idéias a partir de autores que têm discutido a temática, analisar a função docente nas políticas educacionais de cunho neoliberal a partir das contribuições da Psicologia Histórico-Cultural, discutindo a valorização do papel da educação escolar e do professor na formação humana como forma de enfrentamento da intensificação e esvaziamento da profissão.

Considerando que a compreensão sobre tal temática exige um olhar crítico, tendo em vista as forças contraditórias que atuam no direcionamento das políticas educacional e trabalho do professor, a discussão aqui proposta ttem como enfoque principal a compreensão das influências neoliberais na educação a partir de autores que têm analisado tal realidade Barbarói, Santa Cruz do Sul, n.53, p.<49-66>,jan./jun. 2019 
numa perspectiva crítica. Para tanto, a primeira parte do texto busca, a partir das teses de doutorado de Paparelli (2009) e Rossler (2003) e das pesquisas de Assunção e Oliveira (2009), Miranda (2009) e Passone (2014), analisar as influências neoliberais a partir dos anos 1990 nas políticas educacionais e no papel do professor.

No segundo momento, a partir das produções de Vigotski (2003), Facci (2004), Duarte (1998, 2010), Martins (2015) e Rossler, Silva e Moraes (2010), busca compreender as contribuições da Psicologia Histórico-Cultural sobre a educação e o papel do professor como possibilidade de valorizar os conhecimentos científicos e apostar na docência, cuja função é agir de forma intencional, por meio do ensino sistematizado, na construção do conhecimento teórico na formação e desenvolvimento dos estudantes. Nos encaminhamentos finais são retomadas algumas ideias sobre o papel do professor e da educação defendido pela Psicologia Histórico-Cultural e feitos apontamentos no sentido de contribuir no processo de desenvolvimento da consciência do trabalho docente, como prevenção do adoecimento.

\section{Políticas neoliberais após anos 1990: função da educação e do professor}

"Não quero ser professor, pois professor ganha pouco". Não poucas vezes ouve-se essa frase de jovens em processo de escolha profissional, e de tantos outros que estão cursando a licenciatura apenas pelo título de nível superior. Considerando que a constituição subjetiva ocorre na relação sujeito e seu contexto social, percebe-se que o contexto permeado e impregnado pelos valores neoliberais no qual esses jovens vivem e precisam fazer suas escolhas tem considerável influência. E o fato da profissão docente não figurar entre as profissões mais desejadas reflete o contexto macro no qual está inserida.

A categoria trabalho assume em Vigotski, embasado em Marx (2006), a atividade central de constituição do sujeito. A compreensão ontológica marxiana da relação homemnatureza traz a noção de que por meio da atividade intencional (trabalho) o ser humano desenvolve suas potencialidades e, ao mesmo tempo, submete a natureza ao seu domínio. Logo, o homem se diferencia de outros seres viventes, na forma como realiza seu trabalho, isto é, ao modificar a natureza modifica-se a si mesmo, isto é, sua própria natureza. No entanto, com a divisão social do trabalho, e seus desdobramentos, em troca, o homem oferta sua mão-de-obra, que sendo expropriada a partir das relações de exploração, expropria também sua condição ontológica de ser social.

No campo educacional isso se expressa na separação entre quem pensa e quem executa a atividade docente. Conforme Miranda (2005, p. 02) aponta, a crise capitalista do 
modelo fordista/taylorista no início na década de 1970 teve como consequência a necessidade de novos modelos de acumulação de capital. Nesse contexto,

A ideologia Neoliberal logrou as tão esperadas condições históricas para sua
disseminação quando mais uma vez se impôs ao capital a necessidade de
administrar uma crise cíclica. Para tal, não era suficiente só reformar as bases
produtivas utilizando a apropriação do desenvolvimento científico e tecnológico,
mas também as relações sociais, principalmente redirecionando a intervenção do
Estado em favor do mercado e buscando o convencimento da classe trabalhadora à
sua lógica.

A predominância do capital financeiro marca a nova etapa do capitalismo, sendo a sua máxima a produção do lucro. "Sendo assim, a reação do capital à crise foi reorganizar o processo produtivo, gerando uma alteração de forma no padrão de acumulação, aliando a isto novos mecanismos de subsunção, controle e cooptação da classe trabalhadora" (MIRANDA, 2005, p. 02, grifo da autora).

Se o importante nessa sociedade capitalista é a produtividade material, como fica o papel da educação e do professor? Segundo Paparelli (2009) "[...] o trabalho do professor da escola pública é imaterial (seu produto não é um objeto tangível) e não reprodutivo, isto é, não produz mais-valor”. No entanto, a autora reconhece que há contradições entre os autores que discutem a influência do modo de produção do capital na escola pública, de tal modo que existem autores que comparam a escola a uma fábrica (SÁ, 1986), enquanto há autores que acreditam ser a escola totalmente destacada do modelo capitalista de produção.

A crise estrutural do capitalismo dos anos 1970 impôs nova forma de intervenção do Estado. Tal participação era antagônica à forma/mercadoria, ainda que necessária para sustentá-la, pois aumentava a participação do Estado na garantia dos direitos sociais e diminuía a hegemonia capitalista.

No final da década de 1970, como forma de reação à crise, o liberalismo se veste de nova roupagem e, passa a assumir a denominação de neoliberalismo, consistindo essencialmente em uma tentativa capitalista de recompor a primazia e recuperar o âmbito da produção de mercadorias. Para isso, entre outros fatores, nega a crise estrutural e histórica do capitalismo. E, como o foco é a persuasão dissimulada, as políticas de cunho neoliberal têm em seu cerne a produção de capital por meio da disseminação de crenças que procuram encobrir, ao invés de revelar, a natureza real do capitalismo.

Nesse sentido, houve significativas mudanças no mundo do trabalho e na reconfiguração do papel do Estado. Com vista à superação da crise capitalista, os anos 1990 foram marcados por políticas neoliberais tanto no Brasil, como em países latino-americanos, 
de tal modo que, além de alternativa econômica, o ideário neoliberal se configurou também como alternativa teórica, ideológica, ético-política e educativa à crise.

A reconfiguração do papel do Estado é uma das características do neoliberalismo que vem interferindo diretamente na garantia dos direitos sociais, entre eles a educação. Para Paparelli $(2009$, p.15) “[...] a retirada do Estado segundo o ideário neoliberal, consiste tanto na não-intervenção do Estado na economia, quanto na diminuição de participação financeira do Estado no fornecimento de serviços sociais, dentre eles a educação.”

O enfoque educacional dos anos 1990 esteve voltado a promover a equidade social e formar indivíduos para o mercado de trabalho, de forma a garantir mão de obra necessária à expansão capitalista. Num contexto de "[...] flexibilização e desregulamentação do mundo do trabalho e mercantilização de direitos sociais" (MIRANDA, 2005, p. 3), como nova forma de flexibilizar e gerir a produção, profundas mudanças ocorrem na forma de conduzir o sistema escolar e, consequentemente, o papel do professor. O Estado já não assume as responsabilidades pela gestão da educação, delegando a outros setores da esfera privada e de interesse mercantilista (Banco Mundial) tal função, contudo, assume o papel de controle de resultados.

Slogans do tipo "escola de qualidade para todos", "todos pela educação" "Brasil, pátria educadora”, e os mais recentes desmontes da educação pública, arquitetados pelos governos pós anos 1990 definem muito bem o ideário neoliberal. O Estado tem se eximido de sua função na gestão educacional e, a partir das agências de controle internacional, tem delegado à escola e a sociedade civil a responsabilidade por garantir formação da força de trabalho, resolução dos problemas sociais e muitas outras funções numa “[...] lógica gerencial pautada pelos conceitos de produtividade, eficácia, excelência e eficiência” (PAPARELLI, 2009, p. 16), na prática escolar tem contribuído à intensificação do trabalho docente

As demandas delegadas à escola têm contribuído, segundo a autora para a desprofissionalização do professor. Ele faz tudo e, o que parecia ser sua função principal, ou seja, garantir acesso ao conhecimento, fica relegado ao segundo plano. Mas como o professor acredita que seja sua função ensinar, não obtendo êxito neste processo, se culpa pelos resultados negativos do sistema educacional. Além do mais, o Estado, como mecanismo de controle, cobra resultados de acordo com a norma produtivista do capitalismo. Para a autora,

Os valores neoliberais também estão presentes na pedagogia defendida como "moderna", pautada no "aprender a aprender", na pedagogia de projetos, na crítica ao professor conteudista e defesa da escola como espaço de formação de habilidades e competências, na flexibilização e diversificação das estratégias de avaliação (PAPARELLI, 2009, p. 18, grifo da autora). 
Sob essa ótica, Rossler (2003) discute em sua tese de doutorado intitulada "Educação e modismo na educação: processos de alienação na difusão do ideário construtivista" a questão da ideologia neoliberal e pós-moderna que tem direcionado os rumos da educação no Brasil.

[...] baseados em ideários filosóficos, psicológicos e pedagógicos, calcados no lema
aprender a aprender, essas mesmas políticas educacionais vêm, ainda determinando,
por um lado, o empobrecimento dos conteúdos curriculares do ensino básico e
secundário, por meio de sua adaptaçãa pragmática à realidade cultural imediata e
alienada dos alunos. Por outro lado, determinando a secundarização do papel do
educador como transmissor dos conhecimentos produzidos e acumulados pelas
geraçães passadas ao longo da história da humanidade, uma vez que defende a
centralidade do aluno nos processos de ensino-aprendizagem, a construção
autônoma dos conhecimentos, rejeitando, inclusive a objetividade desse
conhecimento, isto é, seu caráter transmissível (ROSSLER, 2003, p. 5-6).

O autor ainda discute como o processo de alienação capitalista interfere diretamente na facilidade com que educadores aderem aos modismos na educação. Sua crítica se refere à facilidade com que os profissionais da educação aderem aos ideários pedagógicos surgidos de tempos em tempos, com pouca ou nenhuma reflexão crítica.

Contudo, é importante destacar o quão preocupante pode ser esta realidade num cenário educacional agonizante e "à espera de um milagre", ainda mais quando se considera a dicotomia existente entre concepção e execução, próprios da estrutura do gerenciamento capitalista. Esses modismos difundidos na lógica neoliberal, por meio do gerenciamento dos processos psicológicos e sociais que vulnerabilizam os indivíduos, contribuem para que tais ideários de cunho ideológico encontrem terreno fértil no coração esperançoso da maioria dos educadores que ainda acreditam na possibilidade de mudança social através da educação.

Vale considerar que para Rossler (2003, p. 7), o problema não está em acreditar em tais propostas, mas na falta de crítica aos pacotes milagrosos aceitos sem autonomia e criticidade, de tal forma que educadores passem a defender "[...] os valores, os princípios, os métodos e as técnicas decorrentes de pensamentos que estejam em voga no momento, muitas vezes sem qualquer consistência e na ausência de uma reflexão crítica e consciente acerca dos seus pressupostos, princípios e implicações”.

Outra característica acentuada do ideário neoliberal na educação se revela nos programas de responsabilização do professor como marca das reformas educacionais com foco em resultados, conforme evidencia o relatório Achieving World Class Education in Brazil: The Next (2010) do próprio Banco Mundial. Na desenfreada luta por resultados positivos, sem as devidas condições de trabalho e de preocupação com educação de qualidade para todos, se intensifica o sistema de bonificação do trabalho docente, mediante resultados positivos nas avaliações externas e/ou de punição se esses resultados não vêm, mesmo que se 
tenha trabalhado de igual forma. Para Passone (2014, p.427) há uma dualidade a respeito do lugar ocupado por esses profissionais,

[...] o lugar que os profissionais da educação ocupam nesta, ora como vilões, que são chamados à responsabilização, ora como heróis, que merecem ser premiados e gratificados. Dito de outro modo, tais discursos enfatizam a centralidade do professor no processo de ensino em detrimento de outras dimensões que são igualmente estruturantes, como a necessidade de recursos e investimentos adequados à educação pública, dentre outros.

Essa realidade delega à escola a responsabilidade pela reforma educacional. No entanto, para promover tal reforma há o forte incentivo à perda de valores éticos e morais historicamente constituídos na educação. No contexto das reformas e cobranças, pressionados por bons resultados, escolas e professores se veem imersos num sistema de competições, valendo a eficiência e produtividade, com o afinco de cumprir regras e determinações superiores e exteriores ao contexto escolar, o primado da ética dá lugar ao da eficácia.

Esses são elementos cruéis de tal ideário que interferem diretamente na profissão, na qual o importante passa a ser a garantia de resultados e bom desempenho, em detrimento dos valores humanos e da dignidade do trabalho. Conforme aponta Passone (2014, p. 435, grifo da autora):

\footnotetext{
A performatividade, segundo Ball, alteraria a percepção que o profissional possui sobre sua própria identidade, tornando-o um ser alienado, que não se reconhece mais em seu fazer, em sua forma de sentir e pensar sua prática na escola, mas apenas nos resultados. Concomitantemente, tal condição produziria o aumento do sentimento de frustração, culpa e incerteza, culminando na "emergência de uma nova subjetividade", cuja principal característica pode ser descrita como um tipo de "esquizofrenia de valores", marcada pelo conflito entre o compromisso/experiência profissional e a aparência da boa performance.
}

$\mathrm{Na}$ lógica da produtividade e do desempenho não há espaço para pensar valores, tais como: o que ensinar e por que ensinar, pois o que o professor acredita e defende tem pouca relevância, quando o que conta é a produção e a maximização do desempenho, “[...] gerando um estado permanente de tensão entre crenças e representação, entre os desempenhos mensurados e os relacionamentos considerados educacionalmente significativos por parte dos profissionais" (PASSONE, 2014, p. 436).

Por isso, com certa angústia e sentimento de impotência, o terreno educacional assiste uma realidade em que professores dos diferentes níveis de ensino, que poderiam permanecer contribuindo com seus saberes científicos e experiências, se eximirem de tal função como forma de enfrentamento ou de cansaço frente a essa lógica que aniquila quem quer ser professor e não apenas "o faz tudo", se sentindo "o faz nada", numa lógica capitalista, pela qual vale mais quem produz mais. 
Autores como Assunção e Oliveira (2009); Oliveira (2006), dentre outros, têm discutido como as lutas pela educação pública, democrática e de qualidade dos anos 1990 chegam à escola trazendo em seu bojo a massificação do ensino e maior intensificação do trabalho do professor, contribuindo para o mal-estar e adoecimento da classe docente.

As novas exigências da profissão docente, sem o devido suporte, na maioria das vezes têm obrigado o professor a trabalhar sob pressão. Assunção e Oliveira (2009, p. 355-356) veem nesse tipo de trabalho um dos graves problemas para o adoecimento do professor.

\begin{abstract}
Ora, trabalhar sob pressão temporal pode desfavorecer o desenvolvimento de estratégias de autoproteção à saúde, como buscar a postura mais confortável, permanecer sentado com o dorso apoiado, evitar abuso vocal. É possível também que o modo operatório mais rápido implique abandonar investimentos em direção à maior aproximação do aluno e das suas necessidades, denotando perda da qualidade e sensação de trabalho inacabado ou objetivo não alcançado.
\end{abstract}

As autoras também pontuam sobre as demandas sociais, tais como cuidados médicos e de higiene, que professores precisam realizar em sala de aula, ao mesmo tempo em que devem permanecer na sala de aula para "cuidar" dos estudantes. O cumprimento de burocracias, como preenchimento de relatórios, diários, entre outros, também contribuem para a intensificação do trabalho docente.

Também há sobrecarga de trabalho quando o professor adoece e falta à escola, pois não há outro para substituí-lo, sobrando para os professores da escola a responsabilidade por cuidar desses alunos. Ou seja, “[...] na ausência do professor os alunos passam a fazer qualquer atividade para se manterem mais ou menos disciplinados dentro das escolas. Estas são situações que trazem consequências diretas para o rendimento ou aproveitamento dos alunos" (ASSUNÇÃO; OLIVEIRA, 2009, p. 360).

A partir do levantamento das pesquisas, Assunção e Oliveira (2009, p. 366) constataram que, dentre os fatores mencionados como responsáveis pela intensificação do trabalho docente e, consequentemente, de adoecimento, cinco foram bastante mencionados: “[...] a) mau comportamento do aluno; b) relações debilitadas com os colegas, diretores e familiares dos alunos; c) pressão temporal; d) perda do reconhecimento da profissão; e) carga de trabalho extensiva".

A carga de trabalho extensiva está estreitamente imbricada na perda do reconhecimento da profissão. Segundo Paparelli (2009), devido ao baixo salário, o professor assume até três contratos, sendo que seu lugar é diferente em cada escola da rede de ensino, o que gera um processo de inclusão e exclusão. Geralmente apenas um contrato é efetivo e os outros são emergenciais, fazendo com que o professor além da sobrecarga de trabalho, exerça 
funções subalternizadas, mesmo entre colegas. Para a autora "[...] na rede pública de ensino está instalada uma lógica excludente que mantém os alunos na escola sem aprender, ou seja, realiza o impedimento do trabalho do professor, estando implicada, portanto, na produção do sofrimento mental do professor" (PAPARELLI, 2009, p. 27).

Dos apontamentos trazidos até aqui pelos autores fica evidente que as políticas educacionais de cunho neoliberal, embora assuma o discurso em defesa da educação e da qualidade do ensino, têm contribuído, na realidade, para a desvalorização do papel da escola e do professor, bem como para o aumento da exclusão social, por não garantir aos estudantes o direito de aprender e de desenvolver o máximo de suas possibilidades que, como pertencente ao gênero humano, tem potencial para desenvolver.

Por isso, a defesa do papel da educação e do professor pelo aporte da Psicologia Histórico-Cultural é apresentada a seguir como contraponto à desvalorização da docência. A partir desta perspectiva, defende-se o papel do professor como essencial na escola pública, como aquele que, ao ter condições de agir de forma intencional e organizada, pode contribuir no processo de construção e de apropriação pelo estudante dos conceitos científicos.

\section{Psicologia Histórico-Cultural: contribuições à valorização do professor e do ensino na escola pública}

As explicações para intensificação e adoecimento da profissão docente, pela ótica da Psicologia Histórico-Cultural, é vista como sendo um processo histórico e social. Nesse sentido, Rossler, Moraes e Silva (2010) reconhecem que os estudos com enfoque na saúde do trabalhador em várias áreas da ciência têm diferentes maneiras e teorias para avaliar a realidade. Essas pesquisas apontam muitas causas para o sofrimento no trabalho, contudo falta criticidade.

Para tais autores, estudos que estejam preocupados com o enfrentamento do sofrimento do trabalhador precisam olhar a realidade macro em que a educação está inserida, pois, não é suficiente “[...] reconhecer as difíceis condições de trabalho; é preciso antes de tudo entender as causas que levam a essa dinâmica. Compreender a raiz dessa realidade significa superar o fenômeno em si e entender as situações concretas de vida que o compõe, a fim de poder transformá-los” (ROSSLER; MORAES; SILVA, 2010, p. 75).

Para compreender tais fenômenos é preciso entender o trabalho tanto como força ontológica, mas também como trabalho alienado nos moldes capitalistas.

O homem se constrói na relação com a natureza, sendo que a esfera social é determinante da atividade humana. Por meio do trabalho o homem se objetiva e se diferencia Barbarói, Santa Cruz do Sul, n.53, p.<49-66>, jan./jun. 2019 
dos outros animais. Portanto, o processo de trabalho "[...] implica necessariamente a unidade de três elementos: 1) a atividade adequada a um fim, isto é, o próprio trabalho; 2) a matéria a qual se aplica o trabalho, o objeto do trabalho e; 3) os meios de trabalho, o instrumental de trabalho" (ROSSLER; MORAES; SILVA, 2010, p. 77).

Garantir esta unidade sob o capitalismo é impossível. Porém há ações que podem contribuir para minimizar as consequências dessa fragmentação no trabalho docente: formação científica fortalecida; maior participação e autonomia docente na definição dos processos de trabalho; melhores condições de trabalho nas escolas com jornadas menos exaustivas e garantia de condições materiais adequadas.

A unidade de tais elementos é essencial para a tomada de consciência, de tal forma que nessa perspectiva não haveria trabalho sem consciência e a consciência não se formaria sem o trabalho. No entanto, quando a unidade é cindida, em vez da formação da consciência do trabalho, constitui-se a perda do real significado da profissão docente.

Estas ações podem contribuir para o planejamento mais consciente do trabalho docente, se constituindo em atividade dirigida e não aleatória. Mas, para que o objetivo seja alcançado de forma consciente é preciso unidade entre quem pensa e quem executa, processo que no capitalismo não é possível, haja vista a natureza fragmentada do trabalho, de modo que quem executa tem pouca relação com quem pensou, por não ser levado em consideração o valor social do trabalho.

A aposta é de que a qualidade da formação científica pode contribuir no processo de tomada de consciência por parte dos profissionais da educação e de sua função nos processos de ensino e aprendizagem, embora nos limites das condições da sociedade capitalista, contribuindo na redução do sofrimento do trabalhador e do esvaziamento da profissão.

Na lógica capitalista, o resultado da produção do trabalho da humanidade fica restrita apenas a um pequeno grupo da população, ou seja, aqueles que possuem os meios de produção. É nesse sentido que o trabalho se torna alienado. Quando não existe unidade entre os três elementos do trabalho, esse se torna alienado em "[...] quatro dimensões interrelacionadas: 1) alienação do homem com a natureza; 2) alienação do homem de si mesmo, de sua atividade vital; 3) alienação do homem com relação ao seu ser genérico; 4) alienação do homem do homem" (ROSSLER; MORAES; SILVA, 2010, p.21).

O homem alienado de sua força de trabalho e de seu ser genérico se torna um alienado de si mesmo, de tal modo que o está alienado também em relação aos outros. Os autores compreendem que nesse processo de alienação, os sentidos humanos, como uma construção 
social também foram alienados - sentido do ter - de modo que as liberdades constituídas historicamente foram substituídas pela única liberdade do comércio.

Por isso, o entendimento sobre o adoecimento do trabalhador perpassa a compreensão dessas dimensões do processo de alienação. Rossler, Moraes e Silva, (2010, p. 86) atribuem a essa ruptura que o sujeito vive, por meio do trabalho desvinculado da construção social da essência humana e da formação da personalidade, “[...] a reflexão sobre a gênese do adoecimento psíquico da classe trabalhadora".

Essa compreensão sobre o trabalho permite análise da educação e do adoecimento do profissional docente não como processo individual, conforme tem sido apontado em muitas pesquisas desse gênero, nem como tem sido tratada nas políticas educacionais, onde os indivíduos são responsabilizados por seus sucessos ou fracassos. Isso porque tal percepção desconsidera as condições, sejam elas de ordem micro do espaço da sala de aula, seja de ordem macro, em relação ao sistema educacional e a sociedade em que está inserido. No que se trata do adoecimento docente, os autores reafirmam a importância de que os problemas, dificuldades e adoecimento de uma classe precisam ser analisados no seu coletivo e contexto histórico.

Por isso, para os autores, ações, sejam por parte da produção do conhecimento científico ou de participação da sociedade, que estejam preocupadas com o enfrentamento do processo de alienação do trabalho, precisam partir da realidade material, das condições dadas. Isso significa compreender que,

[...] esse processo implica que o sujeito aprenda a reconhecer a totalidade de suas determinações, o que motiva sua ação, seus sentimentos e seus pensamentos, colocando-os em relação com suas consequências reais, para si e para os demais. É por meio da análise dessas articulações que as expressões ideológicas da alienação poderão ser identificadas, reconhecidas e assumidas, entretanto, não mais de forma passiva, mas sim criticamente. (ROSSLER; MORAES; SILVA, 2010, p. 94).

Vigotski (2003) defende o trabalho do professor como parte constituinte de sua subjetividade. Ao considerá-lo assim, entende que não pode ser um trabalho alienado, sem que o docente seja parte do processo de concepção e execução. Por tal concepção, reclama a valorização do professor como aquele cuja principal função é ensinar. Ou seja, sua maior responsabilidade é garantir o ensino que promove desenvolvimento, ao invés do papel que tem lhe sido atribuído de promotor da justiça social, como se isso não dependesse de sujeitos bem instruídos como condição de tomada de consciência e de transformação social.

Com base nesse aporte teórico defende-se que a aposta no trabalho mais consciente por parte do professor e com menor grau de sofrimento, implicaria, além de outros aspectos, 
na qualidade da formação inicial e continuada e em condições de trabalho mais digna. Contudo, as exigências impostas à educação pelo ideário neoliberal estão longe de oferecer tais condições. Nas condições postas, a realidade da educação escolar brasileira não oferece garantias de redução do sofrimento docente, considerando que a formação docente defendida pelo organismo internacional, que dita as diretrizes para a educação brasileira, não tem em vista a tomada de consciência da realidade por parte do trabalhador da educação e tampouco investe na melhoria das condições de trabalho.

Vigotski, ao reivindicar ações sobre a essencialidade da profissão docente na Rússia do século XIX, assim se posicionava: “[...] a primeira reivindicação que apresentamos ao professor é que ele seja um profissional cientificamente formado, que seja um verdadeiro professor, que seja um verdadeiro professor antes que um matemático, um lingüístico etc" (VIGOTSKI, 2003, p. 300).

A maioria das pesquisas sobre a intensificação do trabalho docente e adoecimento do professor tem identificado que uma das causas do sofrimento da classe está na falta de preparo do professor para lidar com demandas que exigem dele conhecimentos e tempo de formação, sem que lhes sejam dadas as devidas condições materiais de trabalho nas escolas.

$\mathrm{Na}$ atual situação da educação, dentro da norma vigente capitalista de produtivismo e de acolhimento social, preconizadas nas políticas de cunho neoliberal, a tarefa do professor ficou mais complexa, conforme pesquisa de Assunção e Oliveira (2009) e de Paparelli (2009) já citadas.

Nisso, as palavras de Vigotski (2003, p. 300) continuam muito atuais: “[...] com a crescente complexidade das tarefas exigidas ao professor, a quantidade de recursos que se exigem dele se tornou tão infinitamente diversa e se complicou tanto que, se um professor desejar ser um pedagogo cientificamente formado, vai ter de aprender muito". Contudo, pouco atinentes às mudanças da sociedade que tornam ainda mais complexas a tarefa de ensino-aprendizagem, as políticas educacionais tendem ao pragmatismo, esvaziando a função docente de ensinar.

A defesa de Vigotski é pelo valor da educação, pelo valor daqueles e daquelas que são responsáveis pela apropriação dos conhecimentos historicamente produzidos pela humanidade. $\mathrm{O}$ enfrentamento dos males que afetam a educação, nessa proposta está na valorização do trabalho do professor como aquele que ensina, com condições de pensar e executar o ensino, que seja mediador entre o conhecimento e o estudante. Essa valorização não envolve sobrecarga de trabalho que não tenham como finalidade a formação dos conhecimentos científicos, nem muito menos um trabalho fragmentado. Isso por defender a Barbarói, Santa Cruz do Sul, n.53, p.<49-66>, jan./jun. 2019 
"ideia de que é a educação que leva os homens a se apropriarem dos conteúdos já elaborados pela humanidade e, dessa forma se humanizam”. (FACCI 2004, p. 229)

Apostar nesse papel essencial da escola e do professor pode ser uma das formas de enfrentamento da lógica capitalista em que o importante é a produção material. À escola é demandada a construção de outros valores, pois "[...] por meio da escola são transmitidos conceitos, idéias, valores, símbolos e habilidades, todo o conjunto da produção humana" (FACCI, 2004, p. 229). Nessa mesma linha teórica Duarte (1998, p. 1) defende que o trabalho educativo "[...] alcança sua finalidade quando cada indivíduo singular apropria-se da humanidade produzida histórica e coletivamente, quando o indivíduo apropria-se dos elementos culturais necessários à sua formação como ser humano, necessária à sua humanização", ou seja, produzindo indivíduos singulares.

Para isso, é preciso que o trabalho educativo tenha objetivos claros e definidos, não apenas pelas políticas externas que pensam a educação, mas principalmente pela escola e pelo professor. O professor não pode ser marionete no joguete das políticas neoliberais em seu discurso de educação de qualidade para todos, quando na verdade se executa educação mínima para todos e por todos, ao mesmo tempo em que se exime a função do Estado pela garantia dessa educação.

Pela concepção vigotskiana não é apenas a escola que educa, pois como ser histórico e social aprende-se a partir do contexto em que estar inserido os conhecimentos práticos e cotidianos. Contudo, há conhecimentos que não são aprendidos de tal forma - os conhecimentos científicos. Esses precisam de intencionalidade de quem ensina e de quem aprende. Por isso, na educação escolar, “[...] a humanização do indivíduo é o resultado mais direto do trabalho educativo. Outros tipos de resultado podem existir, mas serão indiretos" (DUARTE, 1998, p. 2).

Por isso, assumir a vertente da Psicologia Histórico-Cultural como possibilidade de discutir formas de enfrentamento da alienação do trabalho docente nas políticas educacionais neoliberais significa apostar no papel afirmativo da educação, como forma de esperança e luta frente ao contexto desalentador para a profissão docente. Para Duarte (1998, p. 3), tal conceito “[...] implica um posicionamento afirmativo sobre o ato de ensinar, isto é, trata-se de construir uma concepção pedagógica que contenha em seu cerne esse posicionamento afirmativo e que, conseqüentemente, se posicione polemicamente em relação às concepções negativas sobre o ato de ensinar".

A defesa de Vigotski é pelo papel primário do professor e do conteúdo na educação escolar e não secundário. Por meio da explicação sobre a zona de desenvolvimento proximal, 
Vigotski (2009) defende o papel essencial do professor, não devendo agir nos níveis de desenvolvimento já alcançados, mas naqueles em que o indivíduo tem possibilidades e potencialidades para desenvolver.

Desse modo, reafirmamos ser a principal função docente ensinar, levando em consideração as possibilidades de cada indivíduo, não em si mesmo, mas como parte da humanidade. Ou seja, não da criança ou do adolescente em si mesmo, mas tendo como referência o adulto mais desenvolvido, trabalhando nas possibilidades de desenvolvimento já alcançados ao longo da história da filogênese e da ontogênese humana.

Apostar nessas possibilidades não é apenas defender o "aprender a aprender", pois como ser social, cada ser humano precisa do outro mais experiente para se apropriar da cultura historicamente construída. Por isso, na escola o papel do professor é essencial para a apropriação dos conhecimentos científicos historicamente construídos. Defender tal posicionamento significa assumir uma postura crítica e necessária frente às demandas impostas ao trabalho docente que tem contribuído a intensificação e ao esvaziamento do significado da profissão.

\section{Retomando algumas ideias}

O discurso da valorização do trabalho docente, na prática, tem-se revelado ambíguo e contraditório. Por um lado defende-se a qualidade da educação e a importância do professor, por outro a função docente como aquela capaz de intervir de forma organizada e intencional na formação dos conhecimentos científicos das novas gerações é secundarizada. Portanto, o esvaziamento do trabalho docente se manifesta como consequência da visão do papel da escola nessa sociedade, a qual é vista de forma ideológica, como aquela que deve dar respostas às demandas sociais, sem, contudo, cumprir seu verdadeiro papel de ensinar.

O esvaziamento da identidade profissional tem como consequências a intensificação e adoecimento do professor, haja vista fatores como: desvalorização de seu papel; pouca formação; exigências burocráticas; falta de sentido da profissão; falta de unidade entre concepção e execução do ensino, dentre outros fatores que têm contribuído para o discurso que fortalece a alienação capitalista no trabalho docente.

Nesse contexto, o aporte teórico da Psicologia Histórico-Cultural defende o papel essencial da escola e do professor no desenvolvimento do ser humano, tendo como horizonte o que o homem como ser genérico tem de mais evoluído. Nessa concepção a valorização do trabalho do professor como parte constituinte de sua subjetividade é essencial, pois o ser humano se materializa por meio do trabalho que envolve finalidade. Logo, quanto mais 
unidade entre os elementos do trabalho, menor será a alienação do trabalho docente. Desse modo, se faz necessária a defesa da função principal da escola como aquela que deve garantir a apropriação dos conhecimentos científicos pelos estudantes e, consequentemente, da

valorização do papel positivo da educação, assumindo postura crítica frente à desvalorização do professor como profissional do ensino.

Por fim, reconhecemos os limites das discussões propostas neste ensaio. No entanto, o intuito foi contribuir com as discussões necessárias sobre o trabalho docente, quando se agrava, cada vez mais, sua desvalorização como profissional, mas por outro lado tem-se delegado, em grande parte, a responsabilidade pela qualidade, ou não, da escola pública ao professor.

\title{
TEACHING WORK: APPRECIATION OR INTENSIFICATION AND EMPTYING OF THE PROFESSION?
}

\begin{abstract}
The study aims to analyze the teaching role in educational neoliberal policies from the Historical-Cultural Psychology, discussing the appreciation of the role of school education and teacher in human formation to face the intensification and emptying of teaching work. From authors who have discussed the neoliberal influence on educational policies it proposes the theoretical framework of Historical-Cultural Psychology as a reflection on ways of confronting the neoliberal ideologies of devaluation of the teaching role. Therefore, identifies the first time the role of education and teacher in educational policies after the 1990s and, in the second, it presents some contributions from the Historical-Cultural Psychology to think the contributive role of education and teacher training in human.
\end{abstract}

Keywords: Neoliberalism. Historical-Cultural Psychology.Teachingwork.

\section{TRABAJO DOCENTE: ¿VALORIZACIÓN O INTENSIFICACIÓN Y DESGASTE DE LA PROFESIÓN?}

\section{Resumen}

Este ensayo tiene por finalidad hacer un análisis del rol del profesor en las políticas educacionales de cuño neoliberal desde la Psicología Histórico-Cultural, discutiendo la valoración del papel de la educación escolar y del profesor en la formación humana como modo de enfrentamiento a la intensificación y desgaste del trabajo docente. Las consideraciones se hicieron llevando en cuenta autores que han discutido el influjo neoliberal en las políticas educacionales y el soporte teórico de la Psicología Histórico-Cultural como modo de reflejar sobre las posibles maneras de enfrentamiento de las ideologías neoliberales de desvalorización del rol docente. Por eso es, que empieza por ubicar el papel de la educación y del profesor en las políticas educacionales tras los años 1900 para después presentar unos cuantos aportes de la Psicología Histórico-Cultural con el fin de pensar en el rol de aporte de la educación y del profesor en la formación humana.

Palabras-clave: Neoliberalismo. Psicología Histórico-Cultural. Trabajo docente. 


\section{REFERÊNCIAS}

ASSUNÇÃO, A.; OLIVEIRA, D. A. Intensificação do trabalho docente. Educ. Soc., Campinas, v. 30, n. 107, p. 349-372, maio/ago. 2009. Disponível em:

<http://www.scielo.br/pdf/es/v30n107/03.pdf >. Acesso em: 18 jun. 2015.

BANCO MUNDIAL. Atingindo uma Educação de Nível Mundial no Brasil: próximos passos - sumário executivo. 2010. Disponível em: Acesso em: 15 set. 2019.

DUARTE, N. Concepções afirmativas e negativas sobre o ato de ensinar. Cad. CEDES v. 19 n. 44 Campinas Abr. 1998. Disponível em:

<https://www.nescon.medicina.ufmg.br/bibliteca/imagem/2085.pdf〉. Acesso em: 19 jun.

2015.

DUARTE, Newton. O debate contemporâneo das teorias pedagógicas. In: MARTINS, Ligia

Marcia; (Org.) Formação de professores: limites contemporâneos e alternativas necessárias. São Paulo: Editora UNESP, 2010, p. 33-49. Disponível em:〈http://books.scielo.org/id/ysnm8/pdf/martins-9788579831034-03.pdf>. Acesso em: 22 dez. 2015.

FACCI, M. G. D. Valorização ou esvaziamento do trabalho do professor? Um estudo crítico-comparativo da teoria do professor reflexivo, do construtivismo e da psicologia vigotskiana. Campinas, SP: Autores Associados, 2004.

MIRANDA, K. A natureza do trabalho docente na acumulação flexível. GT 9 - Trabalho e Educação. 28. Reunião Anual da ANPED. 2005. Disponível

em:<http://www.unicamp.br/cemarx/ANAIS\%20IV\%20COLOQUIO/comunica\%E7\%F5es/G T5/gt5m3c3.pdf >. Acesso em: 20 abr. 2015.

PAPARELLI, R. Desgaste mental do professor da rede pública de ensino: trabalho sem sentido sobre a política de regularização de fluxo escolar. 2009. 194 f. Tese (doutorado). Instituto de Psicologia da Universidade de São Paulo, São Paulo, 2009. Disponível em: <http://www.teses.usp.br/teses/disponiveis/47/47134/tde-07122009-145916/en.php>.Acesso em: 19 abr. 2015.

PASSONE, E. F. K. Incentivos monetários para professores: avaliação, gestão e responsabilização na Educação Básica. Cadernos de Pesquisa, v. 44 n.152 p. 424448abr./jun. 2014. Disponível em:<http://www.scielo.br/scielo.php?pid=S010015742014000200010\&script=sci_abstract\&tlng=pt $>$. Acesso em: 20 abr. 2015.

ROSSLER, J. H. Sedução e modismo na educação: processos de alienação na difusão do ideário construtivista. 2003. 232 f. Tese (doutorado em Educação). Faculdade de ciências e letras, UNESP- Campus Araraquara, Araraquara, 2003.

ROSSLER, J.H.; MORAES, R.J.S; SILVA, G.L.R. A alienação e o sofrimento da classe trabalhadora: contribuições da Psicologia Histórico Cultural. Revista eletrônica Arma da crítica. Ano 2. n. especial, 2010. Disponível em: $\langle$ http://www.armadacritica.ufc.br/phocadownload/artigo_5_especial.pdf $>$. Acesso em: 27 abr. 2015. 
VIGOTSKI, L. S. Psicologia Pedagógica. Trad. Claudia Schilling. Porto Alegre: Artmed, 2003.

VIGOTSKY, L. S. A construção do pensamento e da linguagem. 2. ed. São Paulo: Martins Fontes, 2009.

Data de recebimento: 06/06/2016

Data de aceite: 19/09/2019

\section{Sobre os autores:}

Élida Furtado do Nascimento Pedagoga pela Universidade Federal do Acre. Mestra em Psicologia pela Universidade Federal de Rondônia. Doutoranda em Psicologia pela Universidade Federal do Rio Grande do Norte. Professora assistente pela Universidade Federal do Acre, Campus Floresta. Membro do Grupo amazônico de estudos e pesquisas em psicologia e educação (GAEPE) e do Núcleo de Estudos em Psicologia Histórico-Cultural (NEPHC), filiada a ABRAPEE. Endereço Eletrônico: n_furtado@ hotmail.com

Luís Alberto Lourenço Matos Psicólogo pela Universidade Federal de Uberlândia. Mestre e Doutor em Psicologia Escolar e do Desenvolvimento Humano pelo Instituto de Psicologia da Universidade de São Paulo (IP-USP). Professor associado do Departamento de Psicologia da Universidade Federal de Rondônia e do Programa de Pós-Graduação em Psicologia da UNIR. Membro da ABRAPEE. Endereço Eletrônico: lumatospvh@ hotmail.com

Marli Lúcia Tonatto Zibetti Pedagoga pela Universidade Federal do Mato Grosso do Sul, mestra e doutora em Psicologia Escolar e do Desenvolvimento Humano pela Universidade de São Paulo (2005). Professora da Universidade Federal de Rondônia (UNIR). Líder do Grupo amazônico de estudos e pesquisas em psicologia e educação (GAEPPE), filiada à ABRAPEE e membro do GT Psicologia e Políticas públicas da ANPEPP. Endereço Eletrônico: marlizibetti@yahoo.com.br 